should be rapidly eliminated.

According to Cronin, neither Darwin nor Wallace saw intraspecific altruism as a problem because they slid halfconsciously from the good of organisms to the good of communities, colonies and even species, an elision that G. C. Williams finally brought forcefully to our attention. If treating organisms as units of selection is mistaken, then treating higher-level entities as units of selection is sure to lead to problems. Cronin agrees with Dawkins that genes can function as "replicators whereas organisms, groups and other levels in the hierarchy cannot. Natural selection is about the differential survival of replicators. So genes are the only serious candidates for units of selection." Here I think that Cronin reasons too quickly. Replication is necessary for selection but is not equivalent to it. Organisms are more than 'vehicles'.

Cronin also addresses two other differences between the views of Darwin and Wallace - the role of selection in speciation and the adequacy of a purely naturalistic theory to explain the moral and intellectual attainments of the human species. Wallace was fond of proclaiming that he was more of a darwinian than was Darwin. In the case of speciation he was right. Wallace thought that intersterility arose as an adaptation through natural selection, whereas Darwin thought that it was merely an incidental effect of selection acting on other characteristics. But with respect to the human species, Wallace was anything but a darwinian, because he appealed to supernatural causes. In fact, Darwin and Wallace disagreed with each other so profoundly on so many issues that it seems more than peculiar to claim that these two men were authors of the same theory. They agreed that species evolve but disagreed on just about every other particular of the theory, including the scope and efficacy of natural selection. Cronin points out these differences more dramatically than any previous writer, partly because she has not been afraid of using our current understanding to explain the past.

David Hull is in the Department of Philosophy, Northwestern University, Evanston, Illinois 60208-1315, USA.

- In June 1858, Darwin received Wallace's now famous letter, enclosing an essay in which Wallace described his own theory of evolution. "I never saw a more striking coincidence", Darwin wrote to Charles Lyell. "So all my originality, whatever it may amount to, will be smashed." The letters surrounding these events and the eventual publication of the abstract of Darwin's theory a year later appear in The Correspondence of Charles Darwin: Vol. 7 1858-1859, recently published by Cambridge University Press. Price $£ 35, \$ 59.95$.
Nervous starts

\section{J. Z. Young}

Foundations of the Neuron Doctrine. By Gordon M. Shepherd. Oxford University Press: 1992. Pp. 338. £35, \$39.95.

Cajal's Degeneration and Regeneration of the Nervous System. Translated by R. M. May. Edited by Javier De Felipe and Edward G. Jones. Oxford University Press: 1991. Pp. 769. £60, \$65.

THOSE who probe the nervous system with electrodes probably seldom stop to consider the history of knowledge of the cells they are impaling. Yet it would help them to think about the problems that have arisen in the search for units of nervous activity. Since the days of Santiago Ramón y Cajal, most neuroscientists have depended on a rather simple

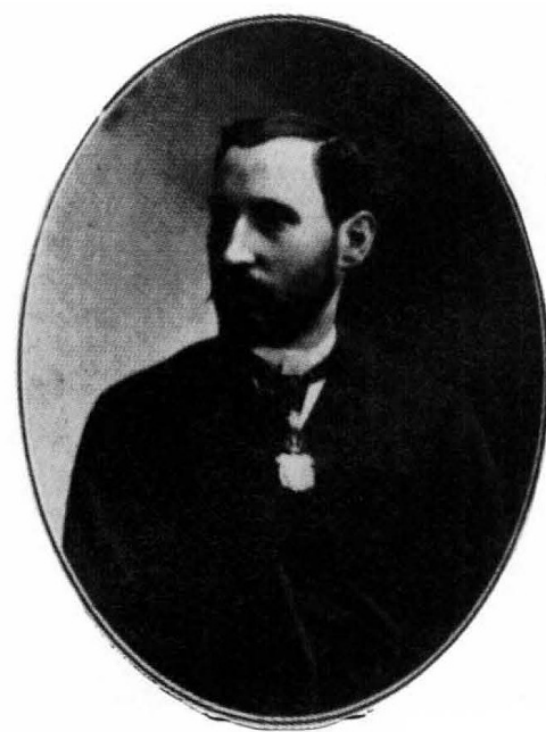

Cajal: proponent of "connection by contact".

picture of the neuron, with dendrites, cell body and axon as the essential unit. This has also been the model mostly used in artificial intelligence. Shepherd's book provides a survey of the history of the neuronal hypothesis. In his last chapter, he raises the question of whether we should now look for units both larger and smaller than the neuron.

The controversy at the end of the last century turned on the question of whether neurofibrils proceed from one cell to the next. It was conducted in fairly ferocious language. Cajal writes of his reticularist opponents, such as Golgi and $\mathrm{A}$. Bethe, as "fanatics with haughty minds, inclined towards mysticism". Finally, in 1917, he is happy to write that "the unhorsed physiologist of Strasbourg [Bethe] decided to abandon the field. Victis honos!"

Cajal was, of course, correct in claiming that "connection is by contact", but his opponents were skilful light microsco- pists and not so far wrong as he supposed. Now that electron microscopy has shown the correct relationships at synapses, we can see that their interpretations were in a sense correct. The finest branches of a nerve fibre may indeed appear to enter the end organ, for instance in the groove at the surface of a muscle fibre. There is no evidence that Cajal realized that it is the completeness of the two membranes that is important. If the finer branches run in a trough, the most honest light-microscope interpretation may be that there is continuity. Cajal's opinion was right, but his figures are almost all drawings.

The advocates of the neuron theory were themselves quite "haughty" and hasty in their rejection of all possibilities of "continuity". We know now that gap junctions may allow passage of ions and small molecules between neurons. Furthermore, there may be complete fusion of nerve cells if they always function together. For instance, the two giant cells of the squid initiate contraction of the muscle sac - and they are completely joined by a bridge: for jetting, both sides of the mantle must contract together. But where impulses are initiated there are synapses. This is a system of "Fused neurons and synaptic contacts", as the paper in which it was described was called in 1939. The fusion is the exception that proves the rule. Nerve fibres can fuse, but where decisions are to be made they are separated by synapses. I remember explaining all this to Sherrington (in about 1938). He looked up at me quizzically and said, "I hope that you are right Young, but I find it hard to believe." It is ironic that the squid's giant fibre synapse, more thoroughly investigated than any other, involves a syncytial postsynaptic fibre. I hope that Cajal would have enjoyed the joke (but I'm not sure that he would).

This history of old doubts and quarrels shows how hard it is to arrive at secure knowledge. As more has been discovered it becomes clear that the classical neuron doctrine needs to be extended. Almost from the start there were doubts as to what the term should include. The word 'neuron', originally suggested by Waldeyer in 1891, comes from the Greek, meaning, literally, tendon or sinew, and was applied through confusion to nerve trunks. Some authors therefore wished to keep the term neuron for the axon, whereas others (paradoxically) tried to use it only for the nerve cell body. Kölliker and others emphasized that the word should be spelled 'neurone'. This usage is still insisted on by some British physiologists and by Cambridge University Press. Shepherd nowhere mentions the history of this spelling. Many people must be puzzled to know which form to use and 
the book could have given authorative guidance. Surely British physiologists and Cambridge University Press should now abandon this pretentious and unhelpful practice and follow the rest of the world.

More serious are the problems raised by the discovery that dendrites may have synaptic outputs and that axons can have inputs from other axons. Moreover, dendrites do not always have graded synaptic responses but may carry voltagegated propagated action potentials, whereas, conversely, some axons do not carry these at all. Shepherd summarizes the effects of such processes: "there is not a fixed correlation of structure and function within the different parts of the neuron; axons and dendrites provide flexible substrates in which a variety of membrane channels and local organelles ... can support different types of physiological properties and function operations .... So although the neuron remains a basic anatomical, physiological, genetic and metabolic unit it contains several levels of local subunits, and is itself a part of larger multineuronal units." Such a neuron has several potentially modifiable parts. It will provide a truer picture for neuroscientists and theoreticians who are trying to model parallel computing systems (although there will be difficulty in constructing them).

It is useful to have, at the same time as this review of the neuron doctrine, a new issue of Cajal's own book on degeneration and regeneration of the nervous system. This was first published in Spanish in 1913-14, the cost of publication being covered by expatriate Spanish physicians in Argentina in honour of Cajal's Nobel prize. It was translated into English in 1928, but without several important sections that are included in the present edition. Complete with Cajal's excellent pictures of his preparations, the new edition makes a wonderfully full account of regeneration. Several of his most important ideas are developed here. Particularly relevant to modern work are the concepts of neurotropism and his studies of regeneration in the central nervous system. It is good to have this book, but it tempts one to complain that Cajal's greatest work, Histology of the Nervous System of Man and the Vertebrates, published in 1899 in Spanish and in 1909 in French, is still not available in English. Illustrated again by Cajal's beautiful figures, that book provides detail of every part of the brain and peripheral nervous system, and should be accessible to every neuroscientist.

J. Z. Young, emeritus professor of anatomy at University College London, is at 1 The Crosslands, Brill, Aylesbury, Buckinghamshire HP18 9TL, UK.

\section{The world's genetic libraries}

\section{Paul Colinvaux}

Diversity and the Tropical Rainforest. By John Terborgh. Scientific American LibraryM. H. Freeman: 1992. Pp. 242. $\$ 32.95, £ 17.95$.

BIOLOGY textbooks talk of rainforests as 'layered', five layers being the favoured number. This postulate (it has been little more) dates to Paul Richards' book The Tropical Rainforest (Cambridge University Press, 1952), the first real compendium of rainforest phenomena. But can plants staked out under the Sun really be expected to form layers, each plant, as it were, assigned to its proper station?

In a fine overview of rainforest law, John Terborgh offers an answer based on the geometry of light and shadow. Tree tops are crude cylinders, inevitably with gaps in between. Light angles down between them, eventually to blend and provide modest but even illumination throughout the day. Shaded trees get their best net energy returns by spreading their canopies in this even light. Add a layer for the darkness of the forest floor, and another for emergent trees as a strategy made possible by year-round productivity, and four-fifths of Richards' layers are explained.

But the greatest oddity of rainforests is their astonishing diversity. The latest spectacular assessment comes from the gassing by Terry Erwin of the canopies of trees of a single species in Panama. This brought down 1,200 species of beetle, most of them new to science. If 13.5 per cent of these beetles were host-specific, if as many of all arthropods were equally host-specific, and if al 50,000 known species of tropical forest tree had an equivalent insect ration, then the world's rainforests hold 30 million species. If, if, if . . .. Nobody actually believes this extrapolation. Perhaps the real figure is a mere three million.

For the trees themselves, Alwyn Gentry made the greatest tally yet, on the lower Rio Napo in Peru. Gentry climbed every tree in a hectare $(10,000$ square metres) to sample flowers, fruits and leaves. The perilous climbing, with ropes and irons, $20-50$ metres into the green mists overhead, took him more than a month. After a year or more of waiting for all of the specialist taxonomists to make their reports, Gentry had shown that 300 species were included in the 606 trees with trunks 10 centimetres or more in diameter. Terborgh notes that Gentry was without assistants because no-one would fund

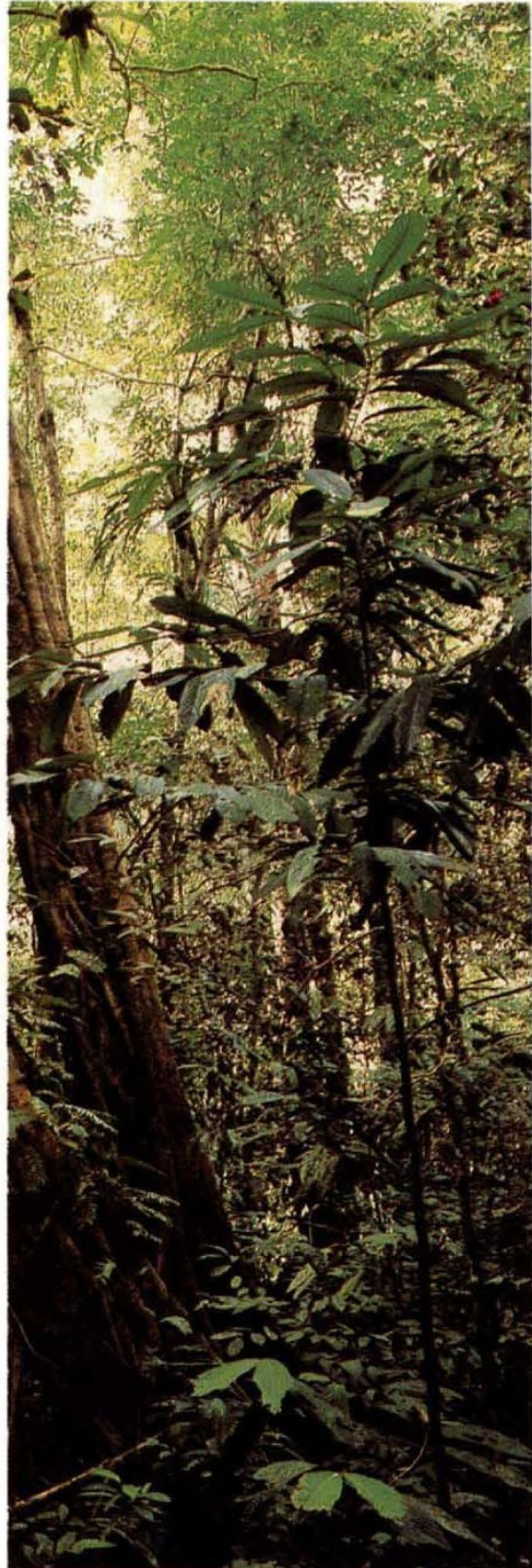

Light and shade encourage development of layered forest. (Picture is taken from The Last Rain Forests edited by $\mathrm{M}$. Collins and published by Mitchell Beazley. Price £17.99.)

this vital work at a sensible level.

How does life in the wet and warm, with no winter, and the Sun at its zenith, allow the packing together of so vast an array? Whole new ways of life are possible, guilds of ant-following birds, for instance, and guilds of fruit and nectar feeders. The area of land for specialism in any temperature regime is far larger at the equator than at high latitudes, theoretically allowing fine separations between species. And so on.

But the most persistent attempts to explain the high diversity of life in rainforests have used the idea of differential extinction. High latitudes have lost their species to extinction in ice ages or from harsh seasonal vicissitudes. Low lati- 